\title{
Language-free graphical signage improves human performance and reduces anxiety when working collaboratively with robots
}

\author{
Iveta Eimontaite ${ }^{1}$ (D) $\cdot$ lan Gwilt ${ }^{2}$ - David Cameron ${ }^{1} \cdot$ Jonathan M. Aitken ${ }^{1} \cdot$ Joe Rolph ${ }^{2} \cdot$ Saeid Mokaram ${ }^{1}$. \\ James Law ${ }^{1}$
}

Received: 31 January 2018 / Accepted: 19 August 2018 / Published online: 21 September 2018

(C) The Author(s) 2018

\begin{abstract}
As robots become more ubiquitous, and their capabilities extend, novice users will require intuitive instructional information related to their use. This is particularly important in the manufacturing sector, which is set to be transformed under Industry 4.0 by the deployment of collaborative robots in support of traditionally low-skilled, manual roles. In the first study of its kind, this paper reports how static graphical signage can improve performance and reduce anxiety in participants physically collaborating with a semi-autonomous robot. Three groups of 30 participants collaborated with a robot to perform a manufacturing-type process using graphical information that was relevant to the task, irrelevant, or absent. The results reveal that the group exposed to relevant signage was significantly more accurate in undertaking the task. Furthermore, their anxiety towards robots significantly decreased as a function of increasing accuracy. Finally, participants exposed to graphical signage showed positive emotional valence in response to successful trials. At a time when workers are concerned about the threat posed by robots to jobs, and with advances in technology requiring upskilling of the workforce, it is important to provide intuitive and supportive information to users. Whilst increasingly sophisticated technical solutions are being sought to improve communication and confidence in human-robot co-working, our findings demonstrate how simple signage can still be used as an effective tool to reduce user anxiety and increase task performance.
\end{abstract}

Keywords Human-robot interaction · Graphical signage · Anxiety towards robots · Flexible manufacturing · Collaborative robotics $\cdot$ Industry $4.0 \cdot$ Technology acceptance

\section{Introduction}

The march of technology is leading us into the 4th industrial revolution (Industry 4.0), where highly connected, intelligent systems will enable processes that are more efficient, productive, and responsive to customer needs and demands [11, 37, 40]. Robotics, particularly in the manufacturing domain, will increasingly replace physically demanding and strenuous manual processes, and those that

Electronic supplementary material The online version of this article (https://doi.org/10.1007/s00170-018-2625-2) contains supplementary material, which is available to authorized users.

James Law

j.law@sheffield.ac.uk

1 Sheffield Robotics, The University of Sheffield, Sheffield, UK

2 Art \& Design Research Centre, Sheffield Hallam University, Sheffield, UK require high precision and repeatability. In response, the role of the human workforce will adapt to make more use of our uniquely human attributes, such as our perceptual and cognitive abilities. For the foreseeable future, human abilities in these areas will continue to surpass those of robots, and effective industrial processes will continue to be reliant on a combination of the two.

Collaborative robotics, or human-robot co-working, is merging these traditionally segregated autonomous and manual modes of operation. New collaborative robots (cobots) allow processes and tasks to be shared between humans and robots, and support safe physical collaboration in shared workspaces. In addition to combining the benefits of automation (speed, accuracy, repeatability, load-bearing capacity) and manual labour (perception, cognition, manual dexterity, flexibility), this technology will give rise to entirely new process possibilities. However, advances in technology must be matched by support and training for users, for whom this will be a revolutionary way of working; without this support, and in the face of current anxieties around robots taking jobs, trust and 
acceptance of the technology will be low. In response, we are exploring engagement with users and utilisation of intuitive communication interfaces, as a means of supporting collaborative working with robots.

Social robotics research routinely demonstrates that experience of human-robot interaction (HRI) can shape an individual's view and their affective response towards robots [6, 7]. For example, people with experience of robots have significantly more positive attitudes towards them than people without [4]. Similar findings have been shown in field studies where retirement home residents who interacted with a mobile robot showed decreased negative attitudes towards robots [41]. Positive outcomes have also been reflected in the cognitive abilities of patients with dementia who have interacted with the Paro robot [50], while interactions with the AIBO robot dog are associated with decreased loneliness [3]. Furthermore, in education, robots have been shown to engage and motivate students, with the result of positively affecting their learning [1, 17]. In sum, interaction with robots in social and educational settings promotes positive attitudes toward robots, and can positively impact on mental well-being.

In manufacturing, the introduction of robots is likely to have a different impact on users. The types of robots, and the situations in which they are applied, are far removed from social and educational settings. Moreover, existing work in HRI for collaborative robotics tends to focus on users already experienced with high-tech automation and robotic systems [51]. Therefore, a key gap exists in understanding how unskilled workers with little experience with robots will be affected by the introduction of robots, and how to facilitate their transition from manual to semi-automated work processes.

To adopt new technology, an individual must be made to feel confident in their abilities with it [25, 44]. Graphical signage supports this by providing information necessary to respond to a given situation, and has many advantages over other communication methods when designed unambiguously and according to ergonomic principles [8, 12]: firstly, it can display clear instructions for individuals with little or no prior experience [45] (for example, Ikea furniture assembly instructions [12]); secondly, graphical signage does not depend on spoken language, making it suitable for multicultural environments and beneficial for non-native speakers [5]; finally, information presented in a succinct way can help people who have learning impairments such as dyslexia, as their cognitive load decreases and they have to process less information compared to written instructions [20]. In short, the benefits of displaying information in a graphical form increase accessibility to a task, with potential benefits of improved performance and well-being [2, 21, 28, 42, 48].
Graphical signage has been shown to help people complete tasks faster and with more accuracy, such as navigating in unfamiliar environments [42, 48], and can reduce the number of accidents in manufacturing and on roads/highways [2, 21]. In addition, graphical signage is often designed to help people understand the requirements of unfamiliar situations, and having such information can lead to greater empowerment and a sense of control [9, 52]. In a healthcare context, well-designed booklets and information leaflets can not only make patients aware of facts and give advice, but also encourage discussion and prompt questions [28]. This leads to the feeling of being in control and able to make important decisions [47], which in turn could decrease experienced stress [22, 36, 38]. Moreover, stress and decision-making anxiety can influence mental and physical illnesses [30], and it is expected that reducing uncertainty through the use of graphical signage can help improve the mental and physical well-being for the individual. Finally, anxiety and negative attitudes towards new technology can affect the level of trust people have towards robot co-workers [18]. This is particularly important in manufacturing settings where an individual's cognitive load is often already high [43] and may not extend to monitoring of co-workers. We propose the introduction of signs that provide hands-free information access, and offer clear and succinct instructions, could reduce cognitive load, and positively affect not only performance on the task but also a worker's well-being.

Although past research shows that HRI experience can decrease a participant's negative attitude towards robots [41], this decrease in anxiety depends on both the robot's behavioural characteristics [35] and the individual's expectation of the experience and interaction; the latter can be communicated and prefigured by the use of graphical signage [31]. The aim of the current research is to examine the impact graphical signage can have on HRI in a manufacturing context, and with novice users.

In this paper, we explore the impact of graphical signage on users of collaborative robots by observing the behaviour of human participants co-working with a robot on a manufacturing-like task. In the remainder of the paper, we describe our methods and results, and demonstrate that graphical signage does indeed improve accuracy and positive emotion in users, and that it can also decrease user anxiety.

\section{Materials and methods}

In [10], we introduced an earlier protocol for assessing the impact of graphical signage on users of collaborative robots. We extend that protocol here by introducing finalized graphical signage and a comprehensive description of 
the measures and procedure for human-robot interaction trials (described in sections 2.4 and 2.5 and provided in Appendix B). Taking into account recent developments in the field (described in Section 1), we have also formed the following hypotheses for testing:

Hypothesis 1 (H1) Use of signs: Users provided with taskrelevant signage will evaluate the presented graphical signs as more effective in supporting task performance than those users presented with the task-irrelevant signage.

Hypothesis 2 (H2) Use of signs: Users provided with task-relevant signage will have better recall of the signs post-experiment than those users presented with the taskirrelevant signage.

Hypothesis 3 (H3) Use of signs: Users provided with task-relevant signage will look at signage longer during the experiment than those users presented with the taskirrelevant signage.

Hypothesis 4 (H4) Task performance: Users provided with task-relevant signage will look at signage longer during the experiment than those users presented with the taskirrelevant signage.

Hypothesis 5 (H5) Affect: Users provided with taskrelevant signage will report decreased anxiety when compared to those users presented with no signage or task-irrelevant signage.

Hypothesis 6 (H6) Affect: Users provided with taskrelevant signage will report decreased negative attitudes towards robots post-experiment when compared to those users presented with no signage or task-irrelevant signage.

Hypothesis 7 (H7) Affect: Users provided with taskrelevant signage will display more positive valence facial expressions throughout the experiment when compared to those users presented with no signage or task-irrelevant signage.

\subsection{Design}

This study used a mixed design of two repeated measures within three independent groups. Repeated measures of attitudes and anxiety towards robots (see section 2.5) were taken pre- and post-HRI task. The three independent groups used were presence of taskrelevant graphical signage (experimental), presence of taskirrelevant graphical signage (active control), and no signage present (baseline control). An active control group was used to account for impact the mere presence of any signage (task-relevant or otherwise) may have on HRI.

\subsection{Participants}

Ninety volunteers from University of Sheffield students and staff participated in the study, 51 were male and 39 were female, $M$ age $=30.12, \mathrm{SD}=11.17$. Participants were evenly distributed across groups (30 per group, Table 3) and offered an opportunity to win one of five $\$ 10$ Amazon vouchers for their participation in the study. It was emphasized that the opportunity to win vouchers did not depend on task performance, only task participation. The study was approved by the University of Sheffield Psychology Department ethics committee.

\subsection{KUKA iiwa robotic arm and API}

The experimental setup was based around interaction with a KUKA LBR iiwa 7 R800 housed in the Sheffield Robotics laboratory. This robot is a lightweight industrial collaborative robotic arm with seven degrees of freedom (Fig. 1). Each of its joints is equipped with torque and position sensing. An application programming interface (API) has been produced [29] for the robot to provide an interface to common middleware applications such as the robot operating system (ROS) [39] and Yet Another Robot Platform (YARP) [27].

Other APIs exist for the KUKA iiwa, such as [19] and [49] that focus on the interaction between operators and the

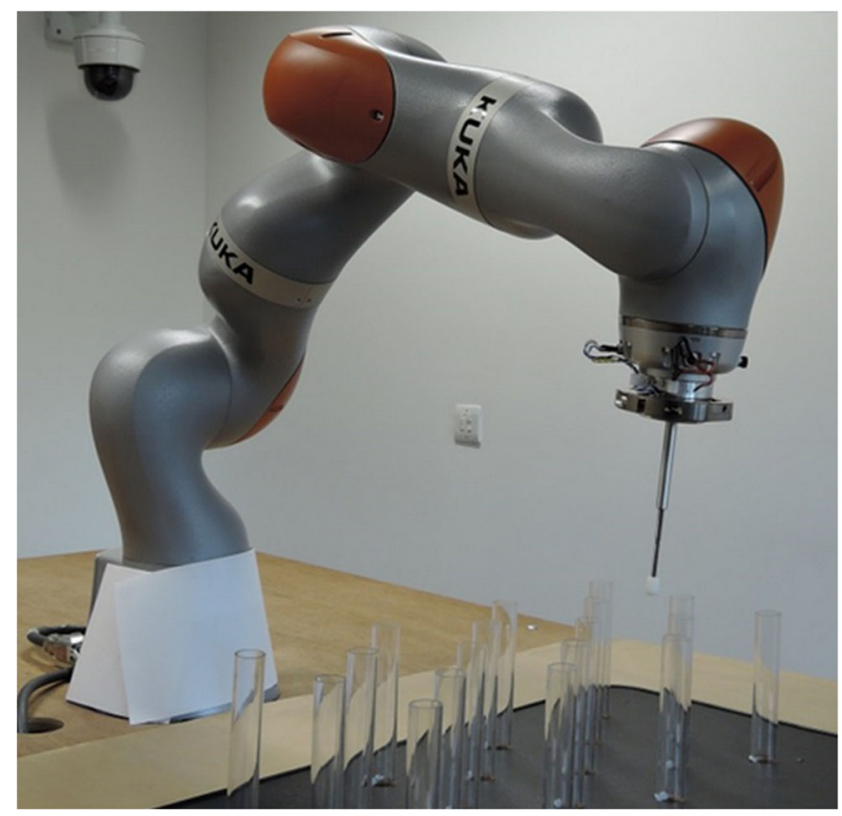

Fig. 1 The KUKA iiwa robotic arm with passive telescopic magnetic end-effector 
robot. Khansari-Zadeh and Khatib [19] focus on learning actions from human demonstration, displaying different impedance to motions for critical parts of the exercise. Virga et al. [49] investigate force-compliant motion within the medical domain. Both of the APIs require specific components installing upon the KUKA iiwa, which require modification of the operational parameters on board the KUKA Sunrise controller; these either change the modes of operation or require custom installation of third-party libraries.

The API used within this paper [29] is a simple, stand-alone application. This can be placed directly on the KUKA Sunrise controller, and provides functionality without necessitating any modification of the control unit. It allows direct integration with ROS, without requiring any configuration. This enables full compatibility with the Robot Systems Toolbox in Matlab and Simulink, which widens the choice of development platforms for API users and allows the inclusion of model-based design as a choice for verifying potential applications [26].

This API was produced to support experiments and interface with other devices, without compromising the levels of safety natively provided. This has enabled the experiments described here, in which participants with no experience of robots are required to physically interact with a robot co-worker on a representative manufacturing task. For this study, the robot was set to be operated in a compliant safe mode ' $\mathrm{T} 1$ ', which placed limits on the speed of motion of the robot and required constant human monitoring (for full details about the robot control, see Appendix A).

\subsection{Graphical language}

A bespoke set of graphical symbols has been developed for this project, designed in accordance with ISO graphical signage conventions $[14,16]$. Eight volunteers, unfamiliar with HRI, were presented with the graphical signage and were asked to identify (1) the meaning of each of the signs in their own words and (2) what changes would help the signs to become clearer. Further refinements and changes to add clarity were undertaken in response to this testing, resulting in the signage depicted in Fig. 2 that represents the following key HRI events:

a The robot arm will move at a certain speed

b The robot arm will move horizontally and vertically

c In your interaction with the robot arm, there will be active and passive states

d You can touch the robot

e You will be within the robot's area of operation

f You should use a certain amount of force to move the robot arm
Due to the structure of the experiment, two sets of signage were developed-signage representing the necessary knowledge required to co-work with the robot (for example, speed and reach parameters of the robot) as seen in Fig. 2, and 'active control' signage which provided visually similar materials but did not provide task-relevant information for the co-worker in this context (for example, optimal temperature for the robot to operate) as seen in Fig. 3.

The project symbols will form the foundation for the development of a more extensive system of symbols that can be used to indicate a range of HRI scenarios.

\subsection{Measures}

The behavioural and self-report (questionnaires) measures are summerised in Tables 1 and 2. Complete versions of the questionnaires are presented in Appendix B.

All the questionnaires (self-report measures) in this study were presented via a computer using the online Qualtrics Insight Platform. Pre-experiment scores on all of NARS $S 1$ and S2, RAS, RTI, participants programming skills, computer usage, and experience with robots were used as a control for between-group differences. Measures with significant differences between groups are included as covariates in further analysis.

\subsection{Procedure}

After signing the consent form, each participant completed an online questionnaire before taking part in the HRI experiment. The questionnaire measured the participant's robot anxiety (RAS), negative attitude towards robots (NARS S1 and S2), computer usage, computer game and programming experience, safety risk taking attitude (RTI), and experience with robots.

Once in the lab, participants were instructed that they were going to be co-working with the KUKA iiwa robotic arm on an HRI task in a manufacturing-type scenario. The KUKA arm was stationed at a 'workbench', along with 18 narrow vertical tubes, six of which contained small bolts (Fig. 4). Participants were instructed that the bolts needed to be extracted from the tubes and placed in storage behind them. The bolts were inaccessible to the human (due to the depth and diameter of the tubes), and while the robotic arm could access each of the tubes, it needed human interaction to direct it to the tubes containing bolts. ${ }^{1}$ As such, the task could be completed only by participants collaborating with the robotic arm. Participants were not provided with further instructions on how to operate the robot.

\footnotetext{
${ }^{1} \mathrm{~A}$ video of the process is available online; https://youtu.be/ 9PWZ2M68Xk
} 
Fig. 2 Complete experimental condition sign with central co-bot activity symbol and information symbols to the left and right hand sides. a Speed. b Movement. c Stop and start. d Touch. e Reach. f Push (see main text for more information)

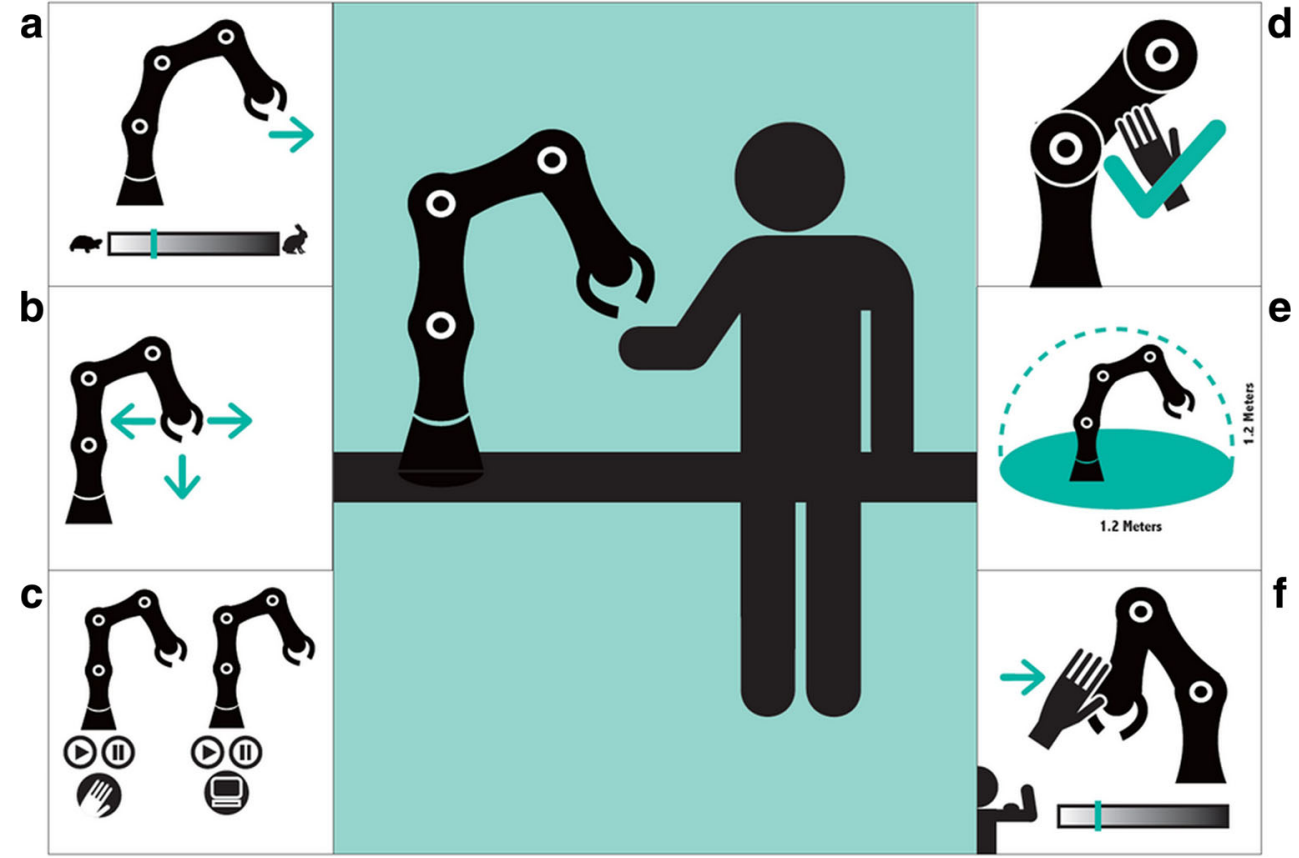

Experimental group participants were provided with graphical instructions indicating that the robot moves slowly, requires gentle force to be moved, and moves only within the specified area (Fig. 2). Robot safety systems would apply a hard stop to the robot should speed, force, or positional limits be exceeded, and the robot would not respond further until the lab assistant conducted a restart procedure. During the experiment, a collaborator observed the participants' performance behind closed curtains as a safety measure in case the experiment needed to be aborted. The maximum time given to complete the task was $10 \mathrm{~min}$.

Participants were informed that they were going to be filmed during the experiment, and the material collected would be used for data coding and further statistical analysis.

All three participant groups were given the same verbal instructions (as above), but only the experimental and the active control groups were presented with graphical signage
Fig. 3 Complete active control sign with central co-bot activity symbol and information symbols not directly relevant to the task performance. a Weight. b Sound. c Temperature. d Do not hit the robot with tools. e Work time. f Not water resistant

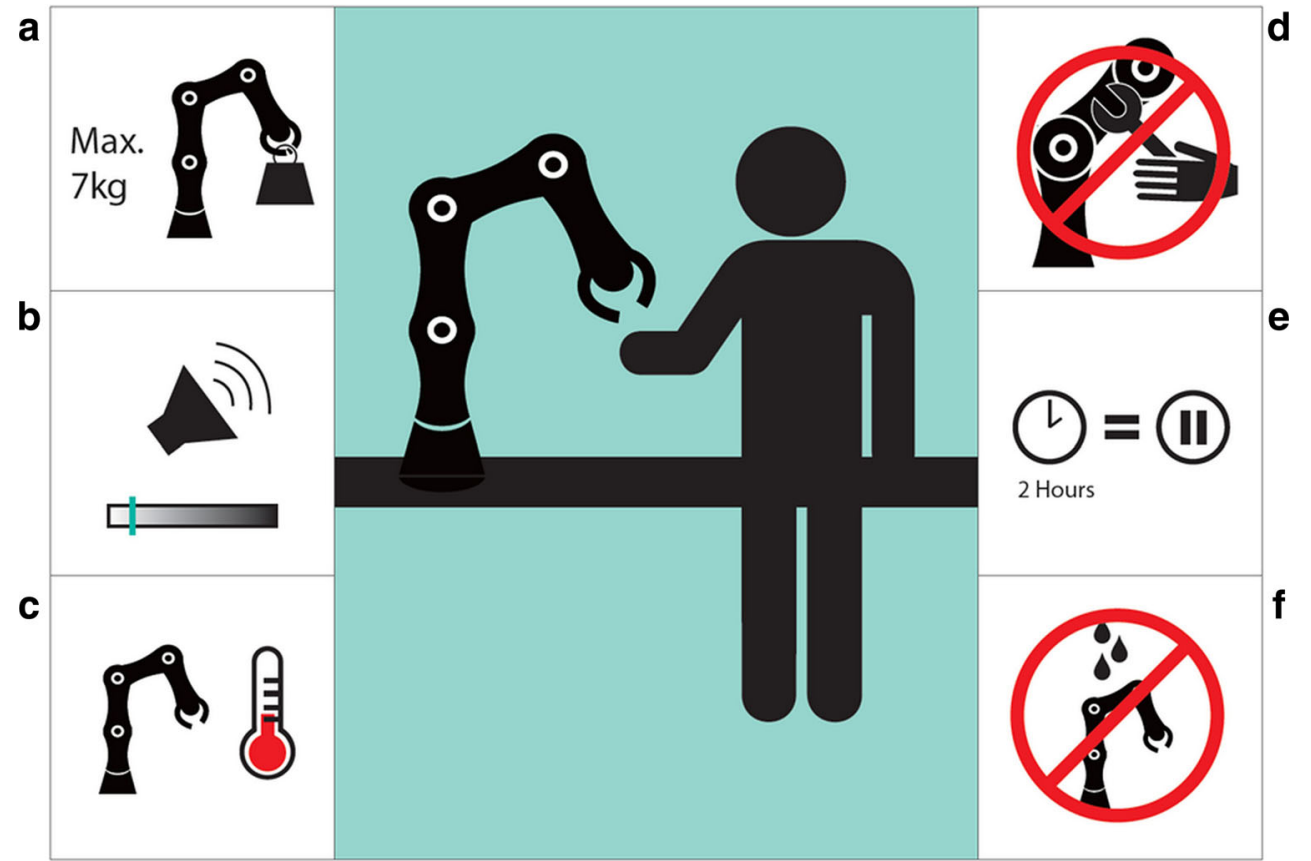




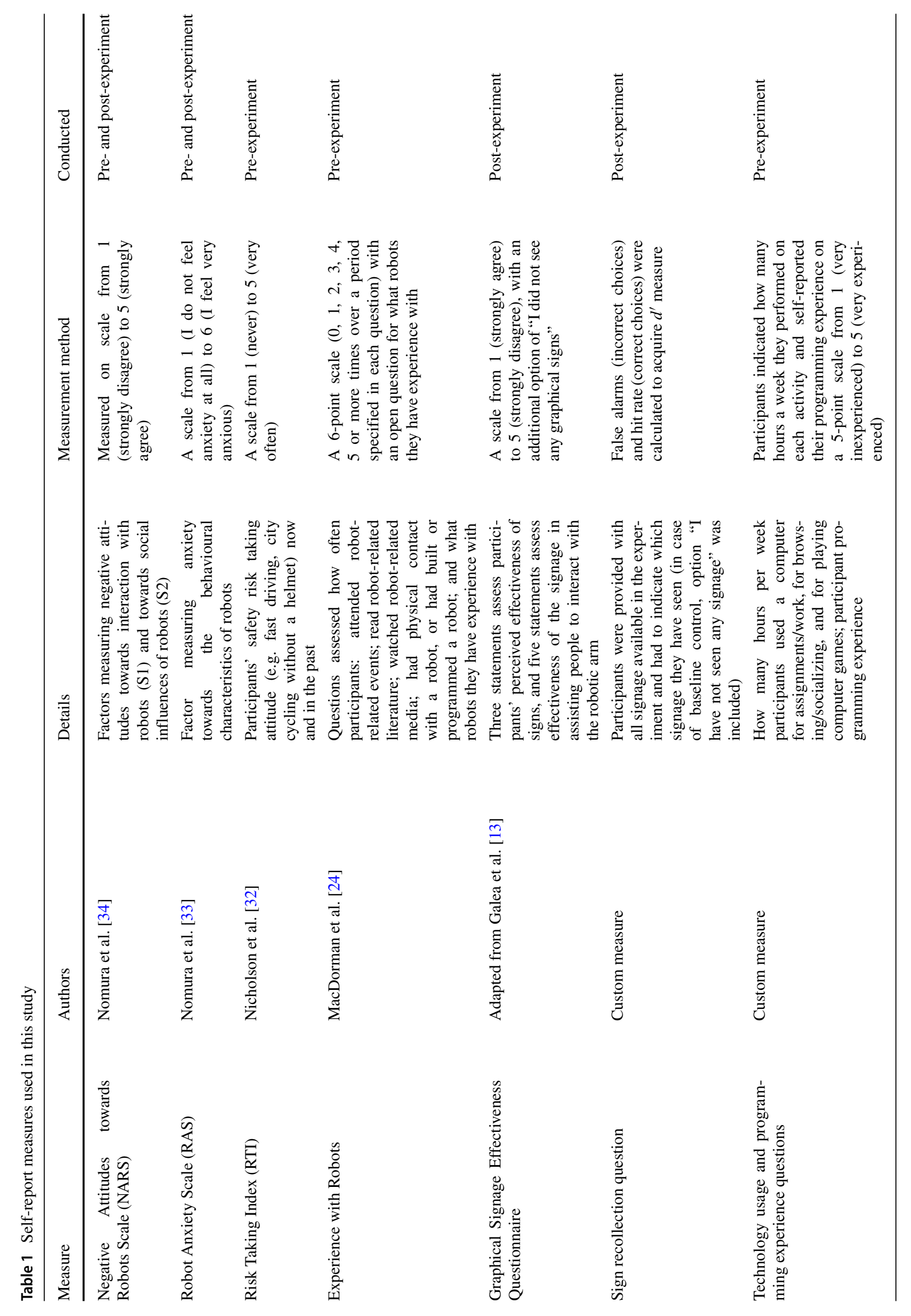



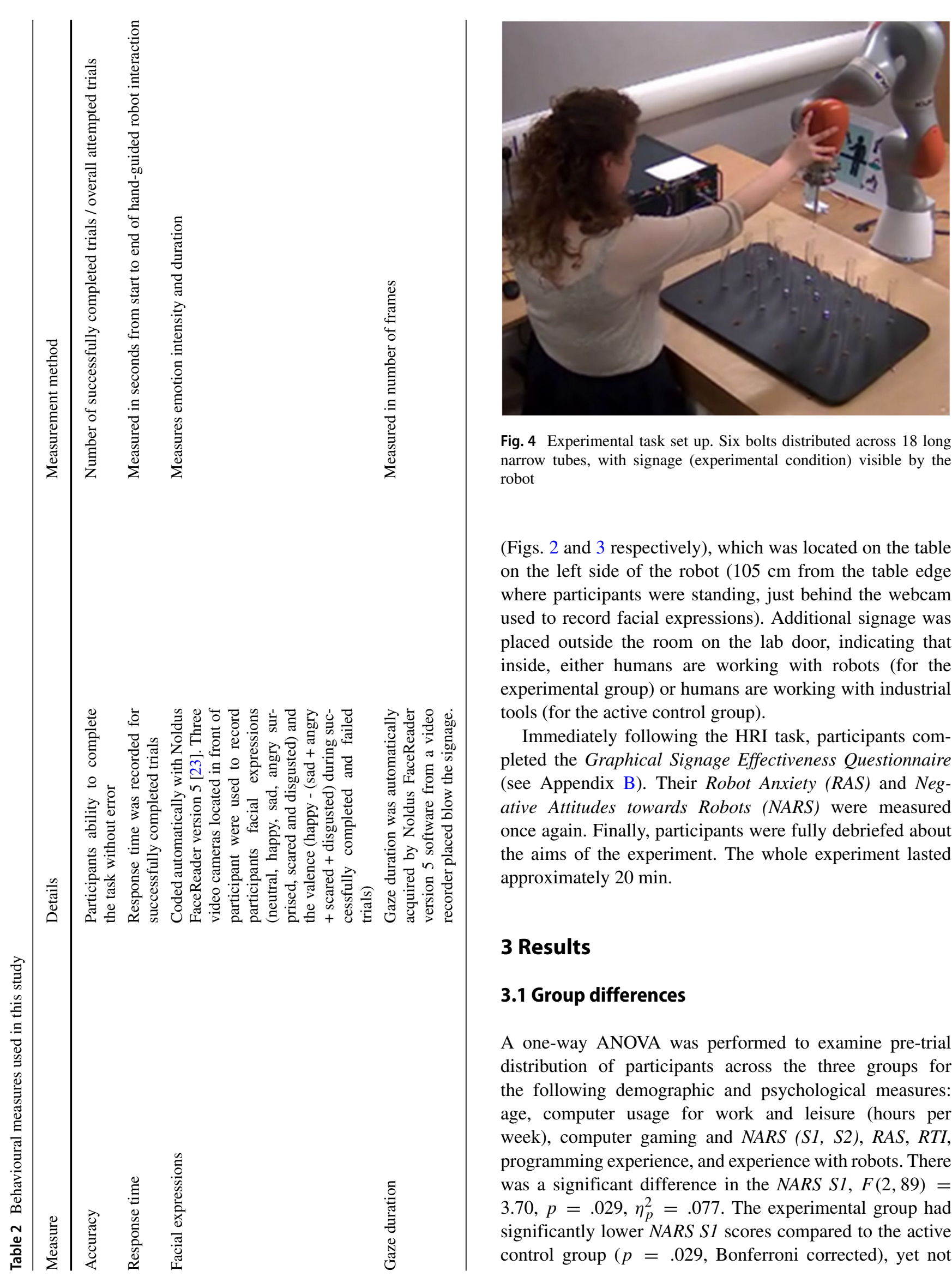

Fig. 4 Experimental task set up. Six bolts distributed across 18 long narrow tubes, with signage (experimental condition) visible by the robot

(Figs. 2 and 3 respectively), which was located on the table on the left side of the robot $(105 \mathrm{~cm}$ from the table edge where participants were standing, just behind the webcam used to record facial expressions). Additional signage was placed outside the room on the lab door, indicating that inside, either humans are working with robots (for the experimental group) or humans are working with industrial tools (for the active control group).

Immediately following the HRI task, participants completed the Graphical Signage Effectiveness Questionnaire (see Appendix B). Their Robot Anxiety (RAS) and Negative Attitudes towards Robots (NARS) were measured once again. Finally, participants were fully debriefed about the aims of the experiment. The whole experiment lasted approximately $20 \mathrm{~min}$.

\section{Results}

\subsection{Group differences}

A one-way ANOVA was performed to examine pre-trial distribution of participants across the three groups for the following demographic and psychological measures: age, computer usage for work and leisure (hours per week), computer gaming and NARS (S1, S2), RAS, RTI, programming experience, and experience with robots. There was a significant difference in the NARS SI, $F(2,89)=$ $3.70, p=.029, \eta_{p}^{2}=.077$. The experimental group had significantly lower NARS $S 1$ scores compared to the active control group ( $p=.029$, Bonferroni corrected), yet not 
Table 3 Control variable mean values (and SD) for experimental, active control, and control groups

\begin{tabular}{|c|c|c|c|}
\hline & \multicolumn{3}{|l|}{ Group } \\
\hline & Experimental & Active control & Control \\
\hline Male/female & $17 / 13$ & $16 / 14$ & $18 / 12$ \\
\hline Age & $29.37(7.95)$ & $31.67(12.89)$ & $29.33(12.26)$ \\
\hline \multicolumn{4}{|l|}{ NARS } \\
\hline $\mathrm{S} 1$ & $10.83(3.00)$ & $13.53(4.49)$ & $11.63(4.21)$ \\
\hline $\mathrm{S} 2$ & $13.33(2.32)$ & $13.60(2.91)$ & $13.37(3.39)$ \\
\hline RAS behavioural & $10.53(4.09)$ & $11.53(4.07)$ & $10.87(5.01)$ \\
\hline Experience with robots & $17.03(8.33)$ & $13.80(8.19)$ & $15.83(8.53)$ \\
\hline \multicolumn{4}{|l|}{ Computer use } \\
\hline Work (h/week) & $28.82(14.81)$ & $24.30(16.67)$ & $23.93(14.12)$ \\
\hline Leisure (h/week) & $14.18(16.54)$ & $11.95(10.82)$ & $11.68(10.68)$ \\
\hline Gaming (h/week) & $2.32(4.11)$ & $1.58(2.51)$ & $4.20(7.74)$ \\
\hline Programming experience & $2.60(1.30)$ & $2.23(1.22)$ & $2.70(1.15)$ \\
\hline \multicolumn{4}{|l|}{ Safety RTI } \\
\hline Present & $1.93(1.01)$ & $2.13(1.17)$ & $2.10(1.18)$ \\
\hline Past & $2.33(1.15)$ & $2.13(1.04)$ & $2.57(1.38)$ \\
\hline
\end{tabular}

significant compared to the control group $(p=.198)$. The difference between the active control and control groups was not significant $(p>.999$; Table 3$)$. There were no further significant differences between groups for any of the remaining pre-test measures $(F(2,89) \leq 1.97, p \geq .145$, $\left.\eta_{p}^{2} \leq .04\right)$. All further ANOVAs are conducted with NARS $S 1$ as a covariate, unless otherwise specified.

\subsection{Effectiveness of graphical signs}

\subsubsection{Gaze}

The ANOVA on gaze duration (measured in number of frames) reveals a significant difference between participant groups for duration of gaze towards the graphical signage (or, for the control group, gaze direction towards the site vacant of signage), $F(2,86)=8.35, p<.001, \eta_{p}^{2}=.163$ (Table 4). Post hoc analysis with Bonferroni adjustment for multiple comparisons revealed that those in the experimental group looked at the graphical signage for longer (number of frames looking at signage/overall number of frames) compared to both the active control $(p=.045)$ and control groups $(p<.001)$, yet there was no significant difference between active control and control groups ( $p=$ .447).

\subsubsection{Sign recollection}

The ANOVA on a $d^{\prime}$ sensitivity analysis for recollection of the graphical signage presents a significant difference between groups for recall of signs, $F(1,57)=5.24, p=$ $.026, \eta_{p}^{2}=.082$ (Table 4). The experimental group had a significantly better recollection of signs than the active control group. To investigate the possibility that better performance during the HRI task is associated with better sign recollection after the task, Pearson's correlation analysis was performed on the experimental group. The results showed that there was no significant relationship between accuracy and $d^{\prime}(r=-.25, p=.176)$, suggesting that the experimental group's better recall of the signage was not associated with their accuracy on the task.

\subsubsection{Graphical signage effectiveness questionnaire}

The questionnaire consisting of eight questions measuring participants' evaluation of graphical signage effectiveness was reliable (Cronbach's alpha $=0.86$ ). Answers from the experimental and active control group on each question were compared using a Mann-Whitney non-parametric test for two independent samples. Control group participants 


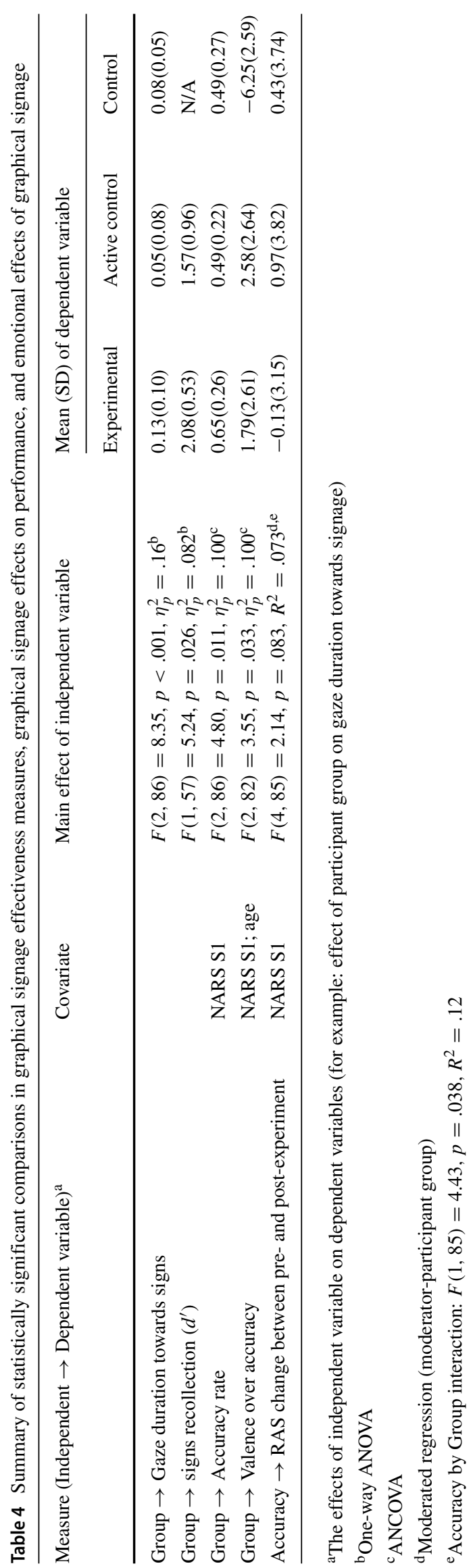

were not included in this analysis as they were not presented with any graphical signage and in the questionnaire indicated that they did not see any signage.

The analysis of experimental and active control groups revealed a significant difference in response to the statement "The graphical sign reinforced my decision concerning how to operate the robotic arm" $(U=279, n=58, p=.022$, $r=.30)$. The experimental group agreed with this statement while the active control group disagreed (Table 5). The differences between groups on other statements were not significant $(U \geq 318, n=58, p \geq .102, r \leq .21)$ except a trend difference for statements "I found graphical signs helpful" and "I found the signs of no use" $(U=312$, $n=58, p=.078, r=.23 ; U=306, n=58$, $p=.068, r=.24$; Table 5). More participants from the experimental group agreed that signs were helpful and disagreed on signs being of no use, while in the active control group, participants disagreed with the statement that signs were helpful and agreed that they were of no use.

Participants in the experimental and active control groups were affected by the signage differently. In comparison to those in the active control group, participants in the experimental group: looked towards the signage for longer, more accurately identified which signs they saw during the experiment, and indicated that signage reinforced their decision on how to operate the arm. Results suggest that the task-relevant signage is used by participants during the HRI scenario, and further analysis was conducted to investigate the impact of signage on task performance.

\subsection{Graphical signage effects on performance}

To investigate if graphical signage had an effect on participants' task performance accuracy rate (collected bolts per number of trials) or response time for successful trials, two separate ANCOVA's controlling for pre-trials NARS S1 with an independent variable of group (experimental, active control, control) were constructed.

\subsubsection{Accuracy rate}

The analysis revealed a significant main effect of group $\left(F(2,86)=4.80, p=.011, \eta_{p}^{2}=.100\right.$; Table 4) and a significant influence of NARS S1 covariate $(F(1,86)=$ $\left.2.12, p=.149, \eta_{p}^{2}=.024\right)$. Further investigation of the main effect of group with Bonferroni post hoc tests revealed that the experimental group had a higher accuracy than the active control $(p=.019)$ or control $(p=.036)$ groups. The difference in accuracy between control and active control groups was not significant ( $p>.999$; Fig. 5). 
Table 5 Percentage agreement for Graphical Signage Effectiveness Questionnaire ${ }^{\mathrm{a}}$ statements

\begin{tabular}{|c|c|c|c|c|c|c|c|c|}
\hline & \multicolumn{3}{|c|}{ Attitudes towards signage } & \multicolumn{5}{|c|}{ Beliefs of signage's support towards HRI task performance } \\
\hline & Confusing & Helpful $^{\text {b }}$ & No use ${ }^{b}$ & Assisted operation & Reinforced decision ${ }^{\mathrm{c}}$ & No difference & Quick decision & Stop hesitate \\
\hline \multicolumn{9}{|l|}{ Experimental } \\
\hline Agree & 70.00 & 50.00 & 26.67 & 50.00 & 50.00 & 26.67 & 26.67 & 63.33 \\
\hline Neither agree nor disagree & 20.00 & 16.67 & 23.33 & 6.67 & 6.67 & 20.00 & 20.00 & 16.67 \\
\hline Disagree & 10.00 & 33.33 & 50.00 & 43.33 & 43.33 & 53.33 & 53.33 & 20.00 \\
\hline \multicolumn{9}{|l|}{ Active control } \\
\hline Agree & 50.00 & 20.00 & 43.33 & 16.67 & 13.33 & 40.00 & 10.00 & 53.33 \\
\hline Neither agree nor disagree & 16.67 & 13.33 & 23.33 & 26.67 & 16.67 & 16.67 & 20.00 & 13.33 \\
\hline Disagree & 26.67 & 60.00 & 26.67 & 50.00 & 63.33 & 33.33 & 63.33 & 26.67 \\
\hline
\end{tabular}

aQuestionnaire responses "slightly agree" and "strongly agree" were combined into the "agree" category, similarly "strongly disagree" and "slightly disagree" were combined into the "disagree" category. The "Neither agree nor disagree" category was left unchanged. This was done only in this table for the ease of viewing results for experimental and active control groups

${ }^{\mathrm{b}} p<.1$

${ }^{\mathrm{c}} p<.022$

\subsubsection{Response time}

The comparison of the average response time between groups with ANCOVA revealed that response times did not significantly differ between groups $(F(2,21.37)=1.75$, $\left.p=.198, \eta_{p}^{2}=.141\right)$.

The analysis shows that the experimental group participants collected more bolts in a lower number of trials compared to the control and active control groups. However, there was no significant difference between the active control and control groups. This result shows that graphical signage relevant to the task helps individuals to be more effective in completing it. The mean response time analysis did not reveal any significant differences between groups. Further analysis of response time change depending on trial number was not possible due to a number of participants successfully completing less than six trials (Table 6).

\subsection{Emotional effects of graphical signage}

So far, the results show that the experimental graphical signage promotes increased accuracy. However, the questions about graphical signage effects on participants' anxiety $(R A S)$ and negative attitudes towards robots (NARS) and their facial expressions (emotions) while interacting with robot are yet to be answered.
Fig. 5 Mean accuracy (collected bolts/number of trials) as a function of group (experimental, active control, control; +/- SE)

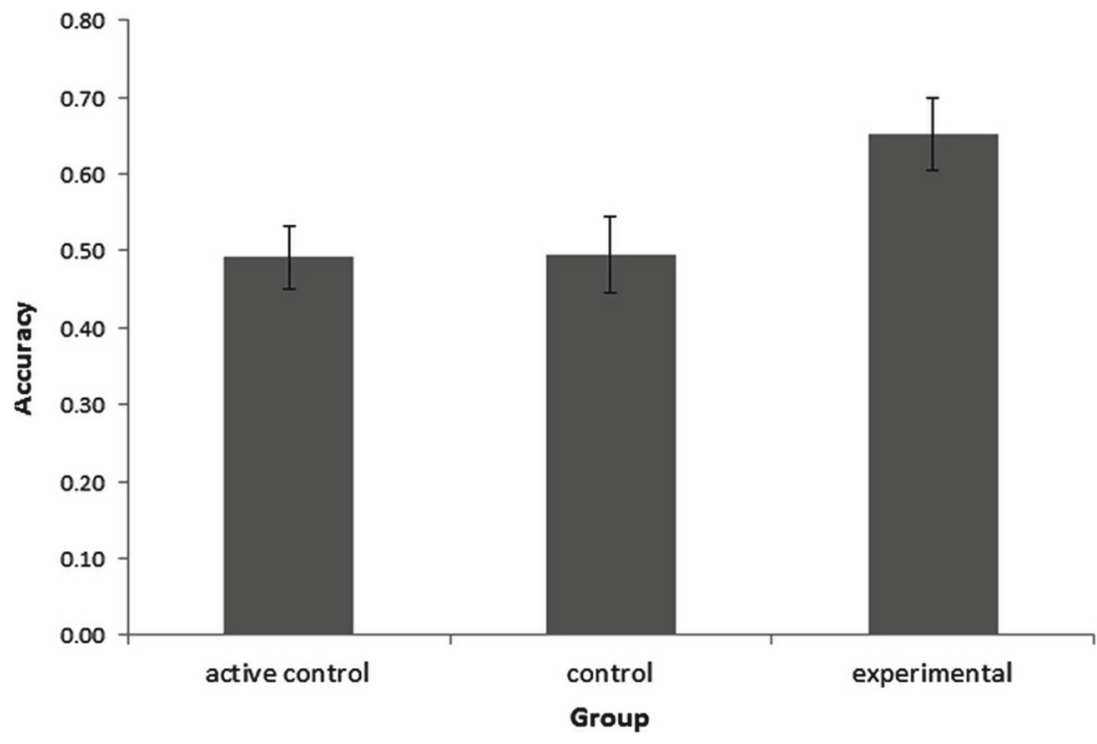


Table 6 Number of successfully completed trials for experimental, active control, and control groups

\begin{tabular}{llll}
\hline Group & \multicolumn{2}{l}{ Trials } & \\
\cline { 2 - 4 } & $0-2$ & $3-4$ & $5-6$ \\
\hline Experimental & 2 & 5 & 23 \\
Active control & 5 & 9 & 16 \\
Control & 4 & 7 & 18 \\
\hline
\end{tabular}

\subsubsection{Robot anxiety and negative attitudes towards robots}

The investigation into whether the graphical signage had an effect on the change between pre- and post-trial $R A S$ and NARS ( $S 1$ and $S 2$ ) scores with ANOVA showed no significant difference between groups $(F(2,89) \leq .71$, $p \geq .496)$.

Three separate moderated regressions for each dependent variable of change between post- and pre-trial $R A S, N A R S$ $S 1$, and NARS S2 were done using PROCESS syntax [15]. In these regression models, the independent variable was accuracy, moderator-participant group (experimental, active control, and control) and covariate was NARS S1.

The main effect of the $R A S$ scores was at a trend significance $\left(F(4,85)=2.14, p=.083, R^{2}=.073\right.$; Table 4$)$, but accuracy by group interaction was significant $\left(F(1,85)=4.43, p=.038, R^{2}=.12\right)$. The group effects of accuracy on the $R A S$ scores change were significant only in the experimental group, $(b=-4.93, t=-2.85, p=$ $.006)$, but not in active control $(b=-1.74, t=-1.23$, $p=.223)$ or control groups $(b=1.44, t=.61, p=.545$; Fig. 6).

The analysis for NARS S1 and NARS S2 scores did not yield significant results $(F(4,85) \leq 1.68, p \geq .162)$.

The results suggest that higher accuracy predicts a greater decrease in the Robot Anxiety Scale, but it is moderated by group. Only the experimental group participants with higher accuracy show a significant decrease in the $R A S$ scores (difference between post experiment-pre experiment scores).

\subsubsection{Facial expressions}

Facial expressions were coded with Noldus FaceReader version 5 software automatically to acquire measures of emotion intensity and duration of seven facial expressions (neutral, happy, sad, angry surprised, scared, and disgusted) and the valence (happy - (sad + angry + scared + disgusted)) [23].

To investigate group differences in intensity and duration of seven basic emotions, one-way between group ANOVA's with within-subject variables of emotion (neutral, happy, sad, angry, surprised, scared, and disgusted) and a betweensubject variable of participant group (experimental, control, and active control), and a covariate of NARS S1 preexperiment score were constructed. The analyses did not show significant differences in intensity of the seven facial expressions overall, successful and failed trials, or emotion duration $(F(2,89) \leq 1.84, p \geq .165)$.

As there was a significant correlation between participants' age and emotional valence over the successful trials (Pearson's $r=-.256, p=.017$ ), and as it has been previously shown that older people have higher emotion control ability [46], an additional analysis was performed to compare the valence of the three participant groups in successful trials (from the point participants touched the robot, until the robot returned to the start position with a bolt), with a covariate of NARS S1 and age. This analysis showed a significant main effect of group $(F(2,82)=3.55$, $p=.033, \eta_{p}^{2}=.08$; Table 4$)$ as well as covariate of age $\left(F(1,82)=7.12, p=.009, \eta_{p}^{2}=.080\right)$, but not NARS $S 1\left(F(1,82)=.34, p=.559, \eta_{p}^{2}=.004\right)$. A Bonferroni post hoc test showed that control group participants had valence at a trend level lower in comparison to active control $(p=.060)$ and experimental groups $(p=.093)$, yet experimental and active control groups did not differ $(p>.999)$. This effect was observed only in valence over the successful trials, but not the failed trials.

The analysis showed that increased accuracy can be a predictor of the decrease in participants $R A S$ scores after the experiment compared to pre-experiment levels, yet this effect was observed only in the experimental group. Furthermore, results from the facial expressions analysis showed that participants having signage (both relevant and irrelevant to the task) have positive emotional valence over successful trials while the 'no signage' participants' valence is negative. It is important to note that the differences were only at a trend level. There were no differences between the groups in failed trials.

\section{Discussion}

The current study explored the effect graphical signage has on participants' performance of a manufacturing-type HRI task. In addition, the Negative Attitudes towards Robots Scale (NARS), the Robot Anxiety Scale (RAS), and facial expressions and emotional valence of the participant during successful and failed trials were recorded. The main results show that participants in the experimental group had higher task completion accuracy than those in the active control and control groups. Furthermore, analysis of facial expression valence over successful trials revealed that both experimental and active control groups had a higher positive emotional valence compared to the control group. However, only in the experimental group did increased accuracy result in decreased anxiety towards robots after the experiment. 
Fig. 6 The effect of accuracy on change in RAS score between post- and pre-experiment moderated by group (experimental, active control, and control) while controlling for the NARS $\mathrm{S} 1$

pre-experiment scores

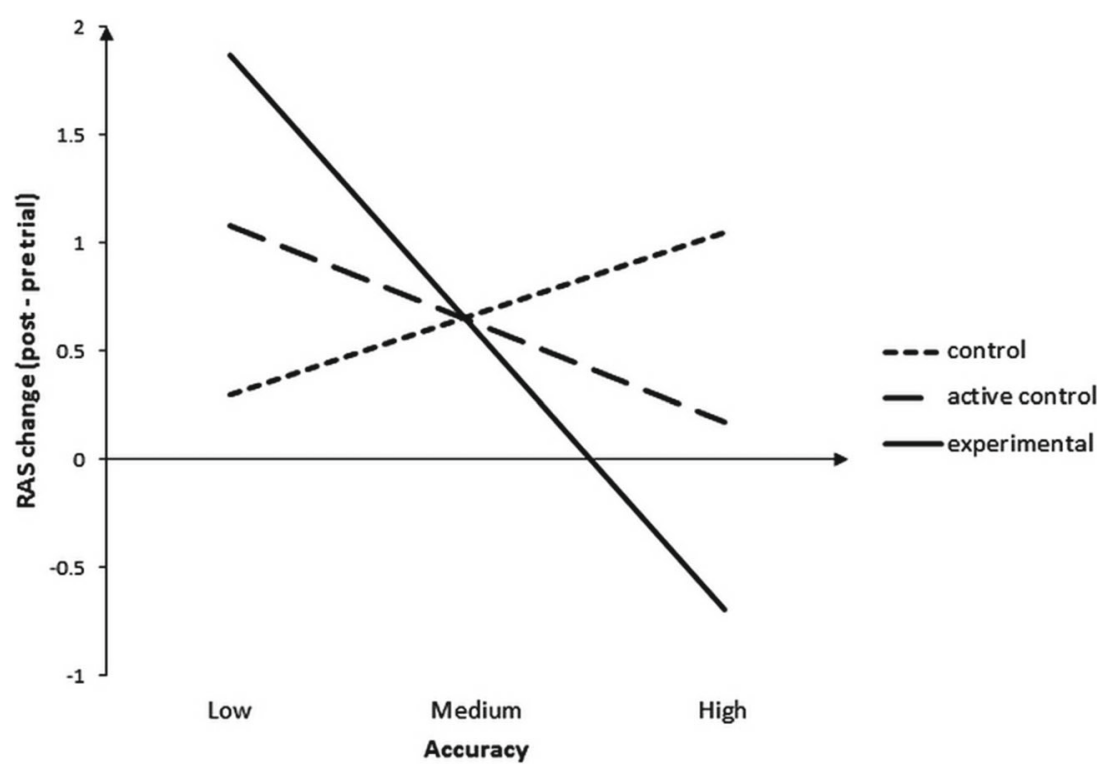

These results cannot be explained by group differences as participants' age, computer usage for work and leisure, gaming, NARS S2, RAS, RTI, programming experience, and experience with robots did not significantly differ between groups. The only significant difference was observed in NARS S1 scores, where the experimental group had significantly lower NARS $S 1$ scores compared to the active control group. As a result, NARS SI was entered as a covariate in further analysis.

Several control measures were taken to consider different effects of signage on the experimental and active control groups. First, the experimental group's gaze duration (frames ratio towards the signage) was significantly higher compared to both control groups, but active control and control group gaze duration to the location of signage did not differ significantly. Second, after the interaction with a robot, $d^{\prime}$ analysis showed that the experimental group recalled the signage more accurately than the active control group suggesting this group's participants were paying more attention to the signage. It is possible that better recollection of the signs reinforces performance, and vice versaperformance on the task reinforces recollection of the signs. However, correlation analysis did not reveal significant association between accuracy and $d^{\prime}$ in the experimental group. This indicates that the experimental group's better recall of the signs was not associated with their accuracy scores on the task.

Finally, the Graphical Signage Effectiveness Questionnaire revealed significant differences between experimental and active control groups regarding the statement that "The sign reinforced my decision concerning how to operate the robotic arm"; the majority of the experimental group participants agreed with the statement whilst the active control group mostly disagreed with this statement. Moreover, a trend difference on the statements "I found graphical signs helpful" and "I found the signs of no use" showed that the experimental group found the signs more valuable for the task performance compared to the active control group. These results indicate that participants were affected by graphical signage differently; in comparison to the active control group, the experimental group looked longer at the signage, had a more accurate recollection of it, and indicated that signage reinforced their decisions of how to operate the robot.

The main finding of the study provides evidence that graphical signage improves accuracy: experimental group participants collected more bolts with less unnecessary trials, and they also triggered hard stops and directed the robot to empty tubes less often. This is consistent with previous studies showing that with more information about a particular task, an individual's accuracy increases; for example, it can result in quicker navigation of unfamiliar settings $[42,48]$ and decreased number of accidents in manufacturing and road safety situations $[2,21]$.

In the current study, graphical signage also affected the participants' anxiety towards robots measured with the $R A S$. The moderated regression showed that with increasing accuracy, post-trial scores on the behavioural subscale of the $R A S$ were reduced compared to pre-trial scores on this scale, but only in the experimental group. A possible explanation lies in participants' sense of empowerment and knowledge of the processes they are going through. Graphical signage is designed to help people understand the requirements of unfamiliar situations, and this information can lead to greater empowerment and a sense of control [47] and decrease the levels of stress experienced [22, 36, 38]. Additionally, negative attitudes towards robots decrease after having interacted with robots [41]; however, the 
decrease in anxiety depends on the robot's behavioural characteristics [35]. In the current study, there was no significant result in the change in negative attitudes (measured with the NARS) before and after the interaction with the robot in the three participant groups. On the other hand, $R A S$ significantly decreased after interaction with the robot in the experimental group. As the signage provides information about the robot's characteristics, most likely it influenced participants' expectations of the robot's abilities and manoeuvrability [31].

Finally, the facial expression analysis revealed differences in facial expression valence on successful trials between the groups. As there was a significant negative correlation between participant age and their emotional valence, age was added as a covariate in this analysis. The comparison of valence between three groups showed higher valence during successful trials in the experimental and active control groups compared to the control group. Past research shows that individuals' emotion regulation improves with age [46], and the trend effect was observed in the current study by controlling for possible age influence on participants' emotion expression. Conversely, the failed trials analysis did not reveal any significant differences. It is likely that the mere appearance of signs is enough to trigger more positive feelings compared to the no signage group, where individuals do not know whether it is possible and safe to interact with robot directly. As the experimental task was not designed to trigger emotions, and in fact its repetitive nature could be used as a baseline for studies exploring emotional processes, further studies are needed to fully investigate differences in emotional valence between groups by exploring participants' emotion regulation and their facial expressions during manufacturing HRI tasks.

\subsection{Limitations and future directions}

There are several limitations to this study. Firstly, the responses on the Graphical Signage Effectiveness Questionnaire indicated that $70 \%$ of participants in the experimental group found signage to be confusing. Lack of clarity is a possible limitation of some of the current graphical stimuli, yet accuracy results across groups suggest that the experimental group still had a better performance compared to the control groups. As there was no significant group difference before the interaction with the robot (NARS S1 was entered as a covariate in the analyses), this only indicates that performance may be further improved with additional development of the signage. To clarify which signs were least clear, we asked four additional participants their opinion of the experimental group signage during the task. The most confusing signs were the active and passive states of HRI (Fig. 2c) and the force necessary to move the robot
(Fig. 2f). The signs showing that an individual can touch the robot (Fig. 2d), and that it moves slowly (Fig. 2a) were indicated to be the most useful. Three out of four participants suggested that having written text or having signs in a particular order resembling the task process would be helpful while working with a robot.

Secondly, the participant population of the current experiment was drawn from university staff and students. Testing the same paradigm with participants from manufacturing industry would provide further insights in the effects graphical signage has on human-robot co-working. The improvements are being incorporated into our further work.

\section{Conclusions}

As collaborative robots are deployed in the workplace, care must be taken to ensure that workers are both accepting of this new technology and are appropriately trained and supported to provide confidence in its operation. Whilst substantial research is being directed towards the technical facets of safe human-robot collaboration, little has been done to address the human factors of trust and acceptance in the workforce. In this work, we have shown, for the first time, how simple instructional signage can improve participants' performance and confidence whilst undertaking a collaborative manufacturing-type task with a robot.

This study involved 90 participants across three groups: an experimental group was presented with graphical signage related to the task, an active control group was presented with irrelevant signage, and a control group was presented with no signage whatsoever. Participants in both the experimental and active control groups showed higher emotional valence, compared to the control group, indicating the mere appearance of signs was sufficient to positively impact on user feelings. However, only in the experimental group were participants significantly more productive, showing that improved robot usability can be attributed to relevant instructional signage. Furthermore, only in the experimental group did the anxiety of participants correspond to their success rate (with greater task success leading to lower anxiety), suggesting a positive feedback loop between signage and successful actions leads to increased confidence.

In this initial study, participants were recruited from an academic environment, and not from a more representative manufacturing workforce. To substantiate our findings, we are embedding our continuing work in manufacturing environments with participants drawn from the industrial workforce. Our initial results are validating those from this study: that instructional graphical signage produces positive emotions in users, improves productivity, and leads to reduced anxiety when reinforced by successful robot operation. 
Funding information The authors acknowledge support from the EPSRC Centre for Innovative Manufacturing in Intelligent Automation, in undertaking this research work under grant reference number $\mathrm{EP} / \mathrm{IO} 33467 / 1$.

Author contribution All authors contributed equally to this work.

Compliance with ethical standards The study was approved by the University of Sheffield Psychology Department ethics committee.

Open Access This article is distributed under the terms of the Creative Commons Attribution 4.0 International License (http:// creativecommons.org/licenses/by/4.0/), which permits unrestricted use, distribution, and reproduction in any medium, provided you give appropriate credit to the original author(s) and the source, provide a link to the Creative Commons license, and indicate if changes were made.

\section{Appendix A: robot control}

The practical human-robot collaborative process used in this experiment was carried out using a KUKA LBR iiwa 7 R800 operating in both hand-guided and autonomous modes. For the purposes of safety, the robot was operated in 'T1' mode. ${ }^{2}$ This resulted in a maximum Cartesian velocity at the end effector of $250 \mathrm{~mm} / \mathrm{s}$.

The position of the robot in Cartesian space can defined by the tuple, Position $=\{X, Y, Z, A, B, C\}$, where $\{X, Y, Z\}$ represents the displacement around the $\mathrm{X}, \mathrm{Y}$, and $\mathrm{Z}$ axes respectively, and $\{A, B, C\}$ represents the rotation about the $\mathrm{X}, \mathrm{Y}$ and $\mathrm{Z}$ axes. A series of $\mathrm{X}-\mathrm{Y}$ tube locations, $\{$ Tubes $\}$, were set up on the table at a height of $\left(Z_{\text {lower }}\right)$. An operating height $\left(Z_{\text {raised }}\right)$ was defined that would allow the telescopic picking tool mounted on the robot to move above freely above the tubes in the X-Y plane with a clearance of around

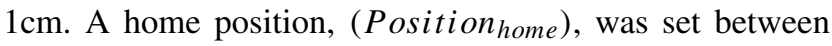
the operator and tube locations, at a height of $\left(Z_{\text {raised }}\right)$.

In hand-guided mode, triggered by applying a $0.2-\mathrm{N}$ force to the wrist of the robot, the operator was able to move the end effector in the X-Y plane but prevented from movement rotationally about each axis and in the Z-plane by restricting the robot's compliance settings. The compliance settings for hand-guided (Compliance Manual) and autonomous (Compliance Auto $_{\text {( }}$ ) modes are shown in Table 7.

\footnotetext{
${ }^{2} \mathrm{~A}$ member of the research team enabled the robot's safety switches whist sat out of view from the participant behind a screen. The researcher monitored participants interacting with the robot via CCTV, and could stop the robot at any time
}

\section{Control algorithm}

The robot control algorithm comprises repeated loops of hand-guided operation followed by autonomous-mode operation. These begin with the robot in the home position, waiting for the operator to enable hand-guiding mode by applying the necessary $>0.2-\mathrm{N}$ force.

Once in hand-guiding mode, the operator is free to move the end effector within the $\mathrm{X}-\mathrm{Y}$ plane above the tube locations. Once the operator releases the robot (i.e. no X-Y forces are applied), the robot switches to autonomous mode and moves to the nearest tube. If the user applies a force, a 3$\mathrm{s}$ timer is started. If an $\mathrm{X}-\mathrm{Y}$ force is applied, the timer is reset so that the the robot remains in hand-guided mode until the forces are removed again and the timer expires. If no X-Y forces are applied, the robot switches to autonomous mode.

Once in autonomous mode, the robot makes a refining move (in the $\mathrm{X}-\mathrm{Y}$ plane) to the nearest known tube location. Once in position, the robot then makes two vertical movements: firstly to $Z=Z_{\text {lower }}$, which places the magnetic probe in contact with potential objects for picking, then back to $Z=Z_{\text {raised }}$, which retrieves picked objects from the tubes. Finally, the robot moves back to the home position for the operator to retrieve any picked objects, and waits for initiation of the next hand-guided sequence. All autonomous end effector motions are linear in $\mathrm{X}-\mathrm{Y}$ or $\mathrm{Z}$ directions, with joint accelerations governed by the KUKA control software.

Pseudo-code for the process described above is given in Algorithm 1.

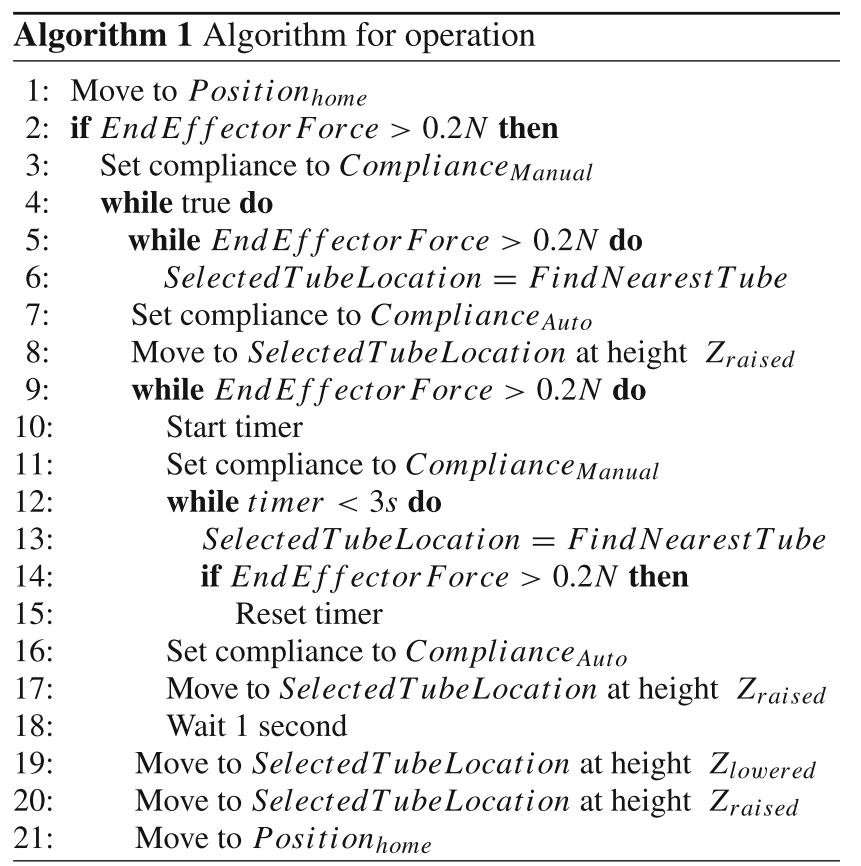


Table 7 Robot parameters in hand-guided and autonomous modes

\begin{tabular}{lllllll}
$\begin{array}{l}\text { Maximum } \\
\text { cartesian } \\
\text { velocity } \\
(\mathrm{mm} / \mathrm{s})\end{array}$ & $\begin{array}{l}\mathrm{X} \text {-Axis } \\
\text { compliance } \\
\left(X_{c}\right)(\mathrm{N} / \mathrm{m})\end{array}$ & $\begin{array}{l}\text { Y-Axis } \\
\text { compliance } \\
\left(Y_{c}\right)(\mathrm{N} / \mathrm{m})\end{array}$ & $\begin{array}{l}\text { Z-Axis } \\
\text { compliance } \\
\left(Z_{c}\right)(\mathrm{N} / \mathrm{m})\end{array}$ & $\begin{array}{l}\text { Rotational } \\
\text { X-Axis }\left(A_{c}\right) \\
\text { compliance } \\
(\mathrm{Nm} / \mathrm{rad})\end{array}$ & $\begin{array}{l}\text { Rotational } \\
\text { Y-Axis }\left(B_{c}\right)\end{array}$ & $\begin{array}{l}\begin{array}{l}\text { Rotational } \\
\text { Z-Axis }\left(C_{c}\right) \\
(\mathrm{Nm} / \mathrm{rad})\end{array} \\
250\end{array}$ \\
\hline 10 & 10 & 5000 & 300 & 300 & $\begin{array}{l}\text { compliance } \\
(\mathrm{Nm} / \mathrm{rad})\end{array}$ \\
250 & 5000 & 5000 & 5000 & 300 & 300 & 300
\end{tabular}

\section{Appendix B: questionnaires}

Questionnaires used in the study:

Fig. 7 Signage recollection question. "Please indicate which signs you have seen during the experiment", shown in Figure 7 (graphics also used in signage effectiveness questions)
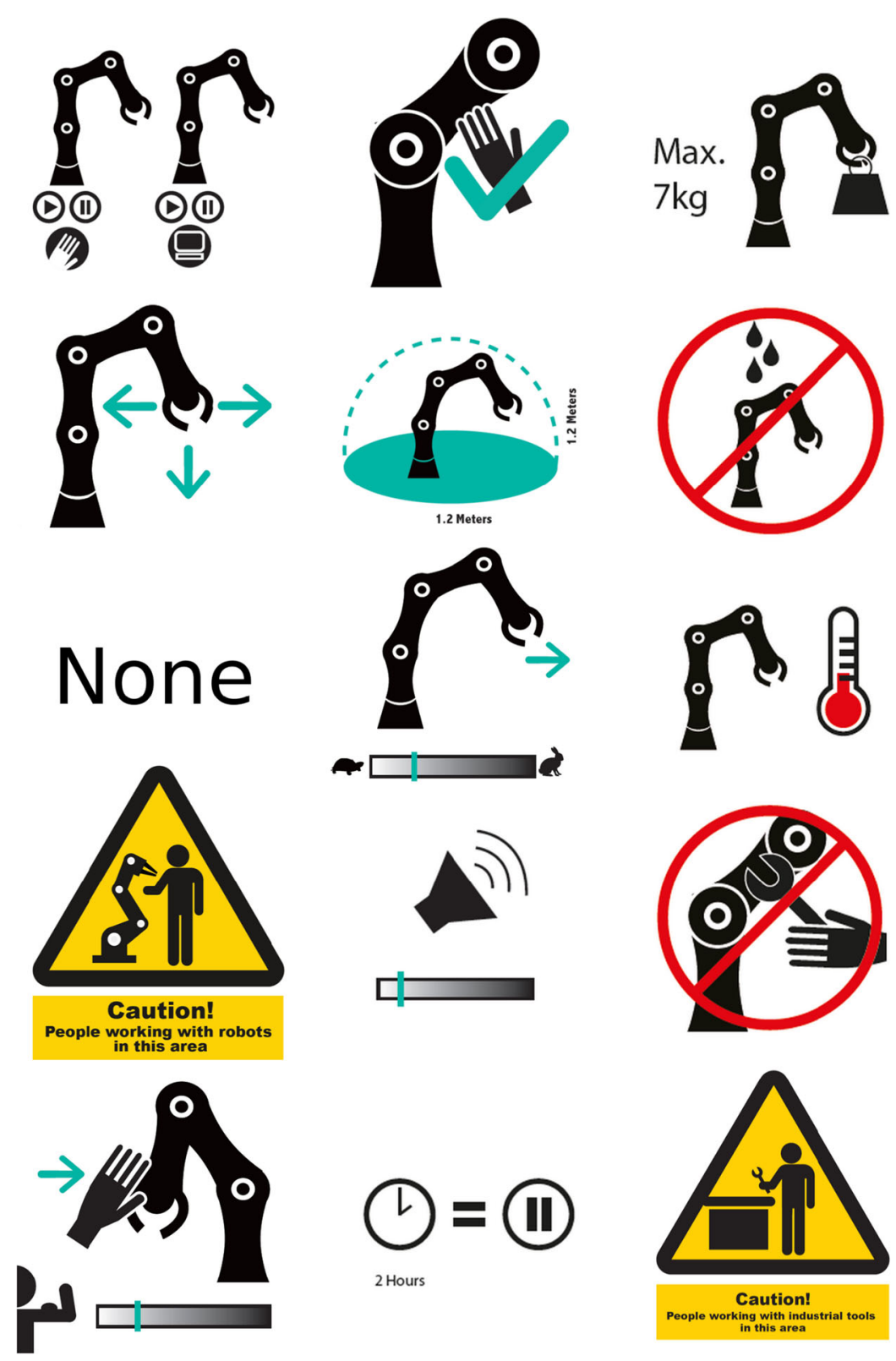
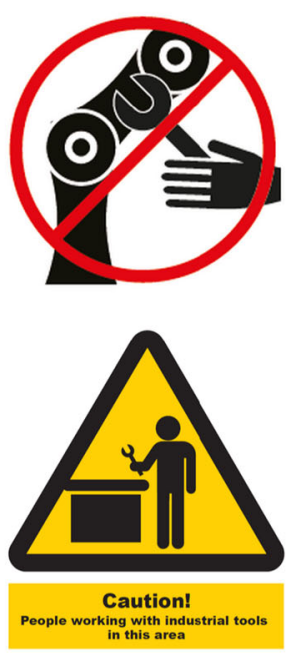
Table 8 Negative attitudes towards robot scale [33]

Strongly Slightly Feel Slightly Strongly

disagree disagree exactly agree agree

neutral

\begin{tabular}{|c|c|c|c|c|c|c|}
\hline S1 - negative & I would feel uneasy if I was given a job where I had to use robots & 1 & 2 & 3 & 4 & 5 \\
\hline attitudes towards & The word "robot" means nothing to me & 1 & 2 & 3 & 4 & 5 \\
\hline \multirow[t]{4}{*}{ interaction with robots } & I would feel nervous operating a robot in front of other people & 1 & 2 & 3 & 4 & 5 \\
\hline & $\begin{array}{l}\text { I would hate the idea that robots or artificial intelligences } \\
\text { were making judgements about things }\end{array}$ & 1 & 2 & 3 & 4 & 5 \\
\hline & I would feel very nervous just standing in front of a robot & 1 & 2 & 3 & 4 & 5 \\
\hline & I would feel paranoid talking with a robot & 1 & 2 & 3 & 4 & 5 \\
\hline \multirow{5}{*}{$\begin{array}{l}\text { S2 - negative } \\
\text { attitudes towards } \\
\text { social influence } \\
\text { of robots }\end{array}$} & I would feel uneasy if robots really had emotions & 1 & 2 & 3 & 4 & 5 \\
\hline & Something bad might happen if robots developed into living beings & 1 & 2 & 3 & 4 & 5 \\
\hline & I feel that if I depend on robots too much, something bad might happen & 1 & 2 & 3 & 4 & 5 \\
\hline & I am concerned that robot would be a bad influence on children & 1 & 2 & 3 & 4 & 5 \\
\hline & I feel that in the future, robots will be commonplace in society & 1 & 2 & 3 & 4 & 5 \\
\hline
\end{tabular}

Participants were asked: "Please indicate your reaction to each of the statements. You will probably find that you agree with some of the statements, and disagree with others, to varying extents. There are no right or wrong answers, just give your first impression without taking too much time"

Table 9 Robot anxiety scale [34] (subscale $S 2$ - anxiety towards behavioural characteristics of robot)

\begin{tabular}{lllllll}
\hline & $\begin{array}{l}\text { I do not feel } \\
\text { anxiety at all }\end{array}$ & $\begin{array}{l}\text { I hardly feel } \\
\text { any anxiety }\end{array}$ & $\begin{array}{l}\text { I do not feel } \\
\text { much anxiety }\end{array}$ & $\begin{array}{l}\text { I feel a } \\
\text { little anxiety }\end{array}$ & $\begin{array}{l}\text { I feel } \\
\text { quite anxious }\end{array}$ & $\begin{array}{l}\text { I feel } \\
\text { very anxious }\end{array}$ \\
\hline How robots will move & 1 & 2 & 3 & 4 & 5 & 6 \\
What robots will do & 1 & 2 & 3 & 4 & 5 & 6 \\
What power robots will have & 1 & 2 & 3 & 4 & 5 & 6 \\
What speed robots will move at & 1 & 2 & 3 & 5 & 6 \\
\hline
\end{tabular}

Participants were instructed: "You will probably find that you feel anxious about some of the statements, and do not feel the same about others, to varying extents. Please indicate your level of anxiety to each of the statements. There are no right or wrong answers, just give your first impression without taking too much time"

Table 10 Risk taking index [32]

\begin{tabular}{|c|c|c|c|c|c|}
\hline & Never & Rarely & Quite often & Often & Very often \\
\hline Recreational risks (e.g. rock-climbing, scuba diving) & 1 & 2 & 3 & 4 & 5 \\
\hline Health risks (e.g. smoking, poor diet, high alcohol consumption) & 1 & 2 & 3 & 4 & 5 \\
\hline Career risks (e.g. quitting a job without another to go to) & 1 & 2 & 3 & 4 & 5 \\
\hline Financial risks (e.g. gambling, risky investments) & 1 & 2 & 3 & 4 & 5 \\
\hline Safety risks (e.g. fast driving, city cycling without a helmet) & 1 & 2 & 3 & 4 & 5 \\
\hline Social risks (e.g. standing for election, publicly challenging a rule or decision) & 1 & 2 & 3 & 4 & 5 \\
\hline
\end{tabular}

We are interested in everyday risk-taking. Please could you tell us if any of these statements have ever applied to you, now or in your adult past? 
Table 11 Prior robot experience [24]

0 times 1 times 2 times 3 times 4 times 5 times or more

How many times in the past one (1) year have you

Read robot-related material

0

(stories, comics, news

articles, product descriptions,

conference papers, journal papers, blogs)

Watched robot-related programs (film, television, DVD, the Internet)

How many times in the past ten (10) years have you

Had physical contact with a robot?

Attended robot-related events

(lectures, exhibitions, trade shows, competitions)

How many times in your life have you built or programmed a robot?*

0

1

2

$3 \quad 4 \quad 5+$

*With which robots do you have experience with, if any?

Participants were asked to indicate the level of agreement with the statements discussing their experience with robots

Table 12 Graphical signage effectiveness questionnaire 1 (adapted from [13])

\begin{tabular}{|c|c|c|c|c|c|c|}
\hline & Strongly disagree & Disagree & $\begin{array}{l}\text { Neither agree } \\
\text { nor disagree }\end{array}$ & Agree & Strongly agree & $\begin{array}{l}\text { Did not } \\
\text { see any signs }\end{array}$ \\
\hline I found the signs confusing & 1 & 2 & 3 & 4 & 5 & 6 \\
\hline I found the signs helpful & 1 & 2 & 3 & 4 & 5 & 6 \\
\hline I found the signs of no use to me & 1 & 2 & 3 & 4 & 5 & 6 \\
\hline
\end{tabular}

Participants were asked to indicate the level of agreement with the statements discussing the signage available during the experiment (Fig. 7)

Table 13 Graphical signage effectiveness questionnaire 2 (adapted from [13])

\begin{tabular}{|c|c|c|c|c|c|c|}
\hline & $\begin{array}{l}\text { Strongly } \\
\text { disagree }\end{array}$ & Disagree & $\begin{array}{l}\text { Neither agree } \\
\text { nor disagree }\end{array}$ & Agree & Strongly agree & $\begin{array}{l}\text { Did not } \\
\text { see any signs }\end{array}$ \\
\hline $\begin{array}{l}\text { The sign assisted me in } \\
\text { selecting how to operate the robotic arm }\end{array}$ & 1 & 2 & 3 & 4 & 5 & 6 \\
\hline $\begin{array}{l}\text { The sign reinforced my decision } \\
\text { concerning how to operate the robotic arm }\end{array}$ & 1 & 2 & 3 & 4 & 5 & 6 \\
\hline $\begin{array}{l}\text { The sign made no difference to my } \\
\text { decision how to operate the robotic arm }\end{array}$ & 1 & 2 & 3 & 4 & 5 & 6 \\
\hline $\begin{array}{l}\text { The sign assisted me to make a } \\
\text { quick decision how to operate the robotic arm }\end{array}$ & 1 & 2 & 3 & 4 & 5 & 6 \\
\hline $\begin{array}{l}\text { The sign made me stop and hesitate } \\
\text { a little while deciding how to operate the robotic arm }\end{array}$ & 1 & 2 & 3 & 4 & 5 & 6 \\
\hline
\end{tabular}

Participants had to indicate the level of agreement with the statements discussing how effective the signage was in its purpose to assist operation of the robotic arm 
Table 14 Technology usage and programming experience questions

\begin{tabular}{|c|c|c|c|c|c|}
\hline & $0-5 \mathrm{~h}$ & $6-10 \mathrm{~h}$ & $11-15 \mathrm{~h}$ & $16-20 \mathrm{~h}$ & $21+\mathrm{h}$ \\
\hline How many hours per week do you use computer for work/ assignments? & 1 & 2 & 3 & 4 & 5 \\
\hline How many hours per week do you use computer for internet browsing/socialising? & 1 & 2 & 3 & 4 & 5 \\
\hline How many hours per week do you play computer games?* & 1 & 2 & 3 & 4 & 5 \\
\hline
\end{tabular}

*What kind of computer games do you usually play?

Participants were asked to indicate their agreement with each statement

Table 15 Programming experience questionnaire

\begin{tabular}{lllll}
\hline & Very inexperienced & Inexperienced & $\begin{array}{l}\text { Neither experienced, } \\
\text { nor inexperienced }\end{array}$ & Experienced Very experienced \\
\hline $\begin{array}{l}\text { How do you estimate } \\
\text { your programming experience? }\end{array}$ & 1 & 2 & 3 & 4 \\
\hline
\end{tabular}

Participants were asked to indicate their programming experience

Publisher's Note Springer Nature remains neutral with regard to jurisdictional claims in published maps and institutional affiliations.

\section{References}

1. Aykin NM, Aykin T (1991) Individual differences in humancomputer interaction. Comput Indus Eng 20(3):373-379

2. Bahar G, Masliah M, Wolff R, Park P (2007) Desktop reference for crash reduction factors. Tech. rep., U.S Department of Transportation, Federal Highway Administration, Office of Safety

3. Banks MR, Willoughby LM, Banks WA (2008) Animal-assisted therapy and loneliness in nursing homes: use of robotic versus living dogs. J Am Med Dir Assoc 9(3):173-177

4. Bartneck C, Suzuki T, Kanda T, Nomura T (2007) The influence of people's culture and prior experiences with aibo on their attitude towards robots. Ai Soc 21(1-2):217-230

5. Ben-Bassat T, Shinar D (2006) Ergonomic guidelines for traffic sign design increase sign comprehension. Hum Factors 48(1):182195

6. Broadbent E, Stafford R, MacDonald B (2009) Acceptance of healthcare robots for the older population: review and future directions. Int J Soc Robot 1(4):319-330

7. Cameron D, Aitken JM, Collins EC, Boorman L, Chua A, Fernando S, McAree O, Martinez-Hernandez U, Law J (2015) Framing factors: the importance of context and the individual in understanding trust in human-robot interaction In: IEEE/RSJ International conference on intelligent robots and systems (IROS). Workshop on Designing and Evaluating Social Robots for Public Settings

8. Chan AH, Ng AW (2010) Investigation of guessability of industrial safety signs: effects of prospective-user factors and cognitive sign features. Int J Ind Ergon 40(6):689-697

9. Cole S (2006) Information and empowerment: the keys to achieving sustainable tourism. J Sustain Tourism 14(6):629-644

10. Eimontaite I, Gwilt I, Cameron D, Aitken JM, Rolph J, Mokaram S, Law J (2016) Assessing graphical robot aids for interactive coworking. In: Advances in ergonomics of manufacturing: managing the enterprise of the future. Springer, pp 229-239
11. European Factories of the Future Research Association et al (2013) Factories of the future: multi-annual roadmap for the contractual PPP under horizon 2020 publications office of the European Union. Brussels

12. Frixione M, Lombardi A (2015) Street signs and ikea instruction sheets: pragmatics and pictorial communication. Rev Philos Psychol 6(1):133-149

13. Galea ER, Xie H, Lawrence PJ et al (2014) Experimental and survey studies on the effectiveness of dynamic signage systems. Fire Safety Sci 11:1129-1143

14. Gwilt I, Rolph J, Eimontaite I, Cameron D, Aitken J, Mokaram S, Law J (2018) Cobotics: developing a visual language for humanrobotic collaborations. In: Proceedings of the cumulus conference

15. Hayes AF (2012) PROCESS: a versatile computational tool for observed variable mediation, moderation, and conditional process modeling. Tech rep., University of Kansas, KS

16. ISO3864-1:2011 (2011) Graphical symbols - safety colours and safety signs - Part 1: design principles for safety signs and safety markings. Standard, International Organization for Standardization, Geneva, $\mathrm{CH}$

17. Kanda T, Hirano T, Eaton D, Ishiguro H (2004) Interactive robots as social partners and peer tutors for children: a field trial. Human-Comput Interact 19(1):61-84

18. Kenworthy JB, Jones J (2009) The roles of group importance and anxiety in predicting depersonalized ingroup trust. Group Processes Intergroup Relat 12(2):227-239

19. Khansari-Zadeh SM, Khatib O (2015) Learning potential functions from human demonstrations with encapsulated dynamic and compliant behaviors. Auton Robot, 1-25

20. Lamont D, Kenyon S, Lyons G (2013) Dyslexia and mobilityrelated social exclusion: the role of travel information provision. $\mathrm{J}$ Transp Geogr 26:147-157

21. Laughery KR (2006) Safety communications: warnings. Appl Ergonom 37(4):467-478

22. Lautizi M, Laschinger HK, Ravazzolo S (2009) Workplace empowerment, job satisfaction and job stress among Italian mental health nurses: an exploratory study. J Nurs Manag 17(4):446-452

23. Lewinski P, den Uyl TM, Butler C (2014) Automated facial coding: validation of basic emotions and facs aus in facereader. $\mathrm{J}$ Neurosci Psychol Econ 7(4):227 
24. MacDorman KF, Vasudevan SK, Ho CC (2009) Does Japan really have robot mania? comparing attitudes by implicit and explicit measures. AI Soc 23(4):485-510

25. Madhavan P, Phillips RR (2010) Effects of computer self-efficacy and system reliability on user interaction with decision support systems. Comput Hum Behav 26(2):199-204

26. McAree O, Aitken JM, Veres SM (2016) A model based design framework for safety verification of a semi-autonomous inspection drone. In: 2016 UKACC 11th International conference on control (CONTROL), pp 1-6

27. Metta G, Fitzpatrick P, Natale L (2006) Yarp: yet another robot platform. Int J Adv Robot Syst 3(1):8

28. Mills ME, Sullivan K (1999) The importance of information giving for patients newly diagnosed with cancer: a review of the literature. J Clin Nurs 8(6):631-642

29. Mokaram S, Aitken JM, Martinez-Hernandez U, Eimontaite I, Cameron D, Rolph J, Gwilt I, McAree O, Law J (2017) A ROSintegrated API for the KUKA LBR iiwa collaborative robot. IFAC-PapersOnLine 50(1):15,859-15,864

30. Moreno-Jiménez B, Rodríguez-Carvajal R, Garrosa Hernández E, Morante Benadero $\mathrm{M}$ et al (2008) Terminal versus non-terminal care in physician burnout: the role of decision-making processes and attitudes to death. Salud Mental 31(2):93-101

31. Muir BM (1987) Trust between humans and machines, and the design of decision aids. Int J Man-Mach Stud 27(5-6):527-539

32. Nicholson N, Soane E, Fenton-O'Creevy M, Willman P (2005) Personality and domain-specific risk taking. J Risk Res 8(2):157176

33. Nomura T, Suzuki T, Kanda T, Kato K (2006) Measurement of anxiety toward robots. In: The 15th IEEE International symposium on robot and human interactive communication, 2006. ROMAN 2006. IEEE, pp 372-377

34. Nomura T, Suzuki T, Kanda T, Kato K (2006b) Measurement of negative attitudes toward robots. Interact Stud 7(3):437-454

35. Nomura T, Shintani T, Fujii K, Hokabe K (2007) Experimental investigation of relationships between anxiety, negative attitudes, and allowable distance of robots. In: Proceedings of the 2nd IASTED international conference on human computer interaction. ACTA Press, Chamonix, pp 13-18

36. Ozer EM, Bandura A (1990) Mechanisms governing empowerment effects: a self-efficacy analysis. J Person Soc Psychol 58(3):472

37. Pawar VM, Law J, Maple C (2016) Manufacturing robotics - the next robotic industrial revolution. Tech. rep., UK Robotics and Autonomous Systems Network

38. Pearson LC, Moomaw W (2005) The relationship between teacher autonomy and stress, work satisfaction, empowerment, and professionalism. Educ Res Quart 29(1):37
39. Quigley M, Conley K, Gerkey B, Faust J, Foote T, Leibs J, Wheeler R, Ng AY (2009) ROS: an open-source robot operating system. In: ICRA workshop on open source software, p 5

40. SPARC The Partnership for Robotics in Europe (2015) Robotics 2020 multi-annual roadmap for robotics in europe. horizon 2020 call ict-2016 (ict-25 \& ict-26) (white paper) release b 03/12/2015 rev a. Tech. rep., EU Commission

41. Stafford R, Broadbent E, Jayawardena C, Unger U, Kuo IH, Igic A, Wong R, Kerse N, Watson C, MacDonald BA (2010) Improved robot attitudes and emotions at a retirement home after meeting a robot. In: 2010 IEEE RO-MAN. IEEE, pp 82-87

42. Tang $\mathrm{CH}, \mathrm{Wu}$ WT, Lin CY (2009) Using virtual reality to determine how emergency signs facilitate way-finding. Appl Ergonom 40(4):722-730

43. Thorvald P, Lindblom J (2014) Initial development of a cognitive load assessment tool. In: The 5th AHFE International conference on applied human factors and ergonomics, AHFE, pp 223-232

44. Torkzadeh G, Koufteros X, Pflughoeft K (2003) Confirmatory analysis of computer self-efficacy. Struct Equ Model 10(2):263275

45. Tufte E, Graves-Morris P (1983) The visual display of quantitative information. Graphics Press, Connecticut

46. Urry HL, Gross JJ (2010) Emotion regulation in older age. Curr Dir Psychol Sci 19(6):352-357

47. Ussher J, Kirsten L, Butow P, Sandoval M (2006) What do cancer support groups provide which other supportive relationships do not? The experience of peer support groups for people with cancer. Soc Sci Med 62(10):2565-2576

48. Vilar E, Rebelo F, Noriega P (2014) Indoor human wayfinding performance using vertical and horizontal signage in virtual reality. Human Factors Ergonom Manuf Serv Indus 24(6):601615

49. Virga S, Zettinig O, Esposito M, Pfister K, Frisch B, Neff T, Navab N, Hennersperger C (2016) Automatic force-compliant robotic ultrasound screening of abdominal aortic aneurysms. In: IEEE International conference on intelligent robots and systems (IROS)

50. Wada K, Shibata T, Saito T, Tanie K (2002) Analysis of factors that bring mental effects to elderly people in robot assisted activity. In: 2002 IEEE/RSJ International conference on intelligent robots and systems, vol 2. IEEE, pp 1152-1157

51. Wilcox R, Nikolaidis S, Shah J (2012) Optimization of temporal dynamics for adaptive human-robot interaction in assembly manufacturing. Robot Sci Syst VIII:441-448

52. Wilkes L, White K, O'Riordan L (2000) Empowerment through information: supporting rural families of oncology patients in palliative care. Aust J Rural Heal 8(1):41-46 